\title{
The ontogeny of locomotion in rats: The influence of ambient temperature
}

\author{
PAUL M. BRONSTEIN \\ Trenton State College, Trenton, New Jersey 08625 \\ MICHELE MARCUS \\ Brooklyn, New York \\ and \\ STEPHEN M. HIRSCH \\ University of Washington, Seattle, Washington 98195
}

\begin{abstract}
Rats aged 15 to 19 days showed persistent locomotor activity when observed in a small open field at $22.8^{\circ} \mathrm{C}$. Higher ambient temperatures greatly curtailed the pups' walking, however. Contrary to prior analyses, the relatively nonattenuating ambulation of rat pups seems to indicate no state of general arousal. The persistent activity among isolated pups does not appear to be a failure to adapt to a novel environment, nor is there much evidence that this behavior represents exploration. The hyperactive state of rat pups reflects a response to their being deprived of the thermal, olfactory, and tactile cues usually found within the litter.
\end{abstract}

Studies of the development of movement in rats have shown that adults and juveniles as young as Day 21 rapidly attenuate their activity when forced into a novel environment. On the other hand, pups of about 15 days postpartum exhibit little activity decrement over tests of 30-45 min (Bronstein, Neiman, Wolkoff, \& Levine, 1974; Feigley, Parsons, Hamilton, \& Spear, 1972). A similar phenomenon has also been noted in immature mice (Nagy, Murphy, \& Ray, 1975).

The understanding of these age-related changes in activity has been limited by the inability of experimenters to specify clearly those stimuli to which the animals are responding. The active 2-week-olds have been described as "exploratory" (Williams, Hamilton, \& Carlton, 1975) or "nonhabituating" (Bronstein, Neiman, Wolkoff, \& Levine, 1974; Parsons, Fagan, \& Spear, 1973). These interpretations, however, seem to be based solely on gross changes in locomotor activity as a function of age. In fact, these abstractions of age-related changes in the rat's locomotor responses are not proven explanations for the phenomenon.

At best, the notion that the active pup is engaging in exploratory behavior might be the hypothesis for subsequent work. Our studies of the possibility that the persistently active juvenile rat is exploring its environment disconfirmed the hypothesis, however. Two-weekold pups do not exhibit spontaneous alternation in a T maze (e.g., Bronstein, Dworkin, \& Bilder, 1974), a response often used to signify exploration in rodents. Furthermore, Palese and Bronstein (1976) showed that

This work was supported by Grant MH26372-01 from the National Institute of Mental Health. Requests for reprints should be sent to Paul M. Bronstein, Department of Psychology, Trenton State College, Box 940, Trenton, New Jersey 08625. persistently active juveniles would not pattern their movements any differently than older animals when tested in a cross maze. There has been no vindication of the statement that the third postnatal week is a period of heightened exploration.

The current paper embodies another orientation toward explaining the change in rats' locomotor persistence during the first postnatal month. The removal of a pup from its nest, littermates, and dam on Day 15, along with the isolated testing of that animal, might be equivalent to social or physiological deprivation for the pup. The heightened and persistent movement of that animal could be determined, primarily, by the abrupt change in the young rat's environment rather than because of any learning (habituation) failure. Isolated 2-week-olds are not capable of adult thermogenesis, but homeothermic regulation of body temperature is typical of pups just a few days more mature (Adolph, 1957; Okon, 1971). Pups typically use social behavior (huddling in a cluster) to regulate their temperatures (Alberts, in press-a, in press-b), and isolated testing completely deprives the subjects of this energyconserving device.

The present studies assessed the role of ambient temperature in the testing chamber on the development of locomotion in rat pups. We expected that by the age of 21 days rats would show a within-sessions decrement in locomotion relatively independent of environmental temperature. The 15-day-olds were hypothesized to display an intratrial drop in activity only at temperatures similar to those found in the maternal nest.

\section{METHOD}

\section{Experiment 1a}

Subjects. Twenty-four Sprague-Dawley albino rat pups 
(two from each of 12 litters) were tested using a longitudinal design; the animals' behavior was monitored when they were $15,17,19,21,23$, and 25 days old. Subjects were conceived and raised from a randomly bred stock obtained initially from Perfection Breeders (Douglassville, Pennsylvania). Pelage markings identified the individual animals. Dams were housed with their own litters in plastic maternity cages with water and Purina Lab Chow available ad lib. The colony room was illuminated $18 \mathrm{~h} /$ day $(0800$ to 0200$)$ and was heated to about $23^{\circ} \mathrm{C}$.

Apparatus and Procedure. Six "animal activity monitors" (Lafayette, Model 86010) were used for testing; these units are cubes ( $25.4 \mathrm{~cm}$ on a side) having plastic bases and surrounded on all sides with aluminum and clear Plexiglas. To control ambient temperature, three of the devices were placed inside each of two incubators (Leahy, Higginsville, Missouri, Model 1200E). One side of each incubator had been replaced by a window through which the rats could be observed. One of the animals in each litter was tested in an incubator warmed to $37^{\circ} \mathrm{C} \pm 1.3^{\circ} \mathrm{C}$; the other littermate experienced a relatively cool test environment $\left(22.8^{\circ} \mathrm{C} \pm 1.6^{\circ} \mathrm{C}\right)$.

Subjects were removed from the nest, placed in separate cardboard containers, and one pup from each litter was placed in each of the environments for a 30-min test. Approximately 3 min elapsed between the removal of a pup from its nest and the start of the trial. Animals were observed for one 5-sec period during each minute of the test; the interobservation interval was $55 \mathrm{sec}$. Using this time-sampling procedure, the behavior of each rat was classified nominally on every observation. The response items tallied were: sniffing, grooming, standing, licking, rearing, lying, and walking. Rats were returned to their nests immediately following testing.

\section{Experiment 1b}

Subjects. This study was a cross-sectional variant of the first investigation; the species, maintenance conditions, and test apparatus were as outlined in Experiment 1a. Ten pups from each of 11 litters were used, with each animal's identity established, as in the first study, by pelage markings. The rats were observed at 15,18 , or 21 days of age at one of three ambient temperatures $\left(22.8^{\circ} \mathrm{C} \pm 1.6^{\circ} \mathrm{C}, 27.8^{\circ} \mathrm{C} \pm 1.6^{\circ} \mathrm{C}\right.$, or $\left.37.2^{\circ} \mathrm{C} \pm 1.3^{\circ} \mathrm{C}\right)$.

Apparatus and Procedure. Pups were tested on only one occasion, every litter contributing a single subject to each of the nine age-by-temperature conditions. The 10th animal in each litter served as a nest-temperature control. This rat's rectal temperature was recorded daily immediately following its removal from an undisturbed nest; a YSI Model 43 thermistor was used along with a Model 402 probe. Each subject's rectal temperature was recorded following testing and prior to the animal's return to the nest.

\section{RESULTS}

In each study walking was by far the most prevalent response. Inactive lying was observed with the second greatest frequency, and the two responses accounted for approximately $75 \%$ of all observations. Also, walking and lying frequencies were inversely related. Animals that ambulated infrequently spent much of their time lying, typically with their ventral surfaces contacting the apparatus floor. Responses other than walking and lying occurred rarely. Consequently, only the data on walking frequency are presented. This response provides an accurate index of each subject's general activity.

Abbey and Howard (1973) and King (1970) have shown that litter identities might account for a sizeable fraction of between-groups variance, which is often erroneously attributed to the independent variable. Furthermore, Stanley (Note 1) has suggested that dogs from different litters show different rates of thermoregulatory development. To avoid the possible overestimation of our effects, age and ambient temperature were considered as within-subjects variables. That is, when rats from a given litter were treated differently, their behavior was analyzed as if a single animal had been tested on multiple occasions. One degree of freedom was assigned to each litter.

In both experiments, the frequency of walking observations was accumulated for every $5 \mathrm{~min}$ of the 30-min testing period. Hence, there were three withinsubjects variables in both studies: age, ambient temperature, and 5-min blocks. Analyses of variance were employed with alpha set at .05 unless otherwise indicated.

\section{Experiment 1a}

As predicted, variations in ambient temperature affected the activity of younger pups more than older animals. Figure 1 depicts the reliable interaction of Age by Temperature $[F(5,60)=7.98, p<.01]$. Sign tests showed that at 15 and 17 days of age animals tested in the warmer environment were less active than littermates run at the cooler temperature ( $p \leqslant .004$ for both). At 19 days of age, the difference due to ambient temperature was nearly reliable $(p<.07)$. Environmental temperature failed to exert a reliable effect on the three older groups of pups.

The variables of age, temperature, and intratrial blocks also had reliable effects upon ambulation $(p<.01$ for all). Activity was inversely related to both age and ambient temperature, and there was a within-sessions decrement in walking responses as testing progressed. This latter effect is seen in Figure 2. Furthermore, the Temperature by Blocks and Age by Blocks interactions were statistically significant $(\mathrm{p}<.05$ for both). The within-sessions activity decrement was more pronounced at the higher temperature. Also, the younger rats exhibited a smaller minute-to-minute drop in activity than the older subjects.

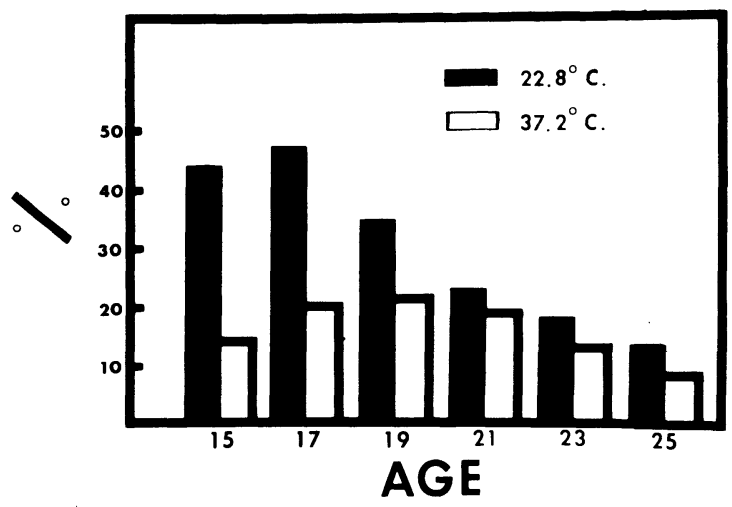

Figure 1. The percentage of observations during which walking responses were noted as a function of age and environmental temperature for Experiment 1a. 


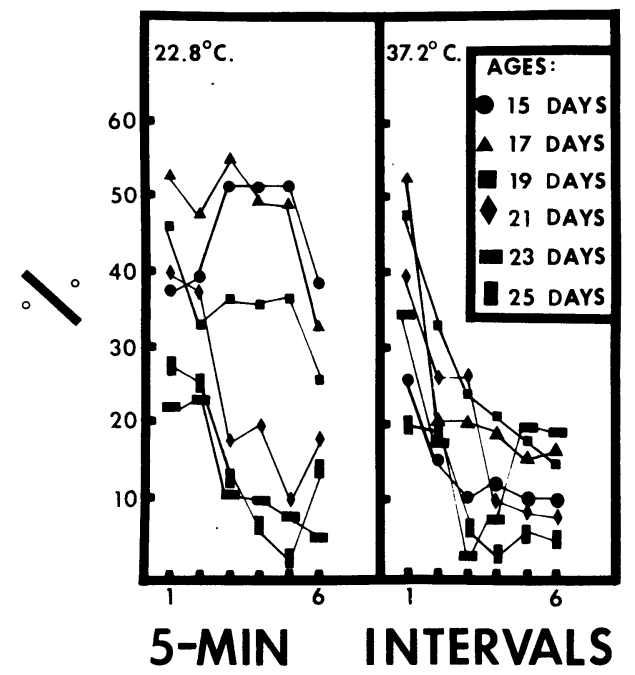

Figure 2. The interaction of age, ambient temperature, and intratrial intervals as these variables affect the relative frequency of walking responses in Experiment 1a.

Finally, the Age by Temperature by Blocks interaction approached significance $[\mathrm{F}(25,300)=1.43$, $\mathrm{p} \cong .05]$. This three-way interaction, along with post hoc tests, indicates that 15-, 17-, and 19-day-olds behaved distinctively when tested in the cooler environment. As can be seen in the left panel of Figure 2, the three -groups tended to maintain their initial levels of activity for most of the 30-min test. Friedman two-way analyses (Siegel, 1956) indicated that none of the three groups showed a significant within-sessions fall in activity. With the exception of the 15-day-olds tested at the high temperature, all other groups showed a withinsessions deterioration of activity. This latter group failed to exhibit the expected decrement because of their extremely low levels of activity from the very outset of testing.

\section{Experiment 1b}

The second study essentially showed that the results of Experiment 1a could be replicated in a cross-sectional design. Figure 3 indicates the reliable interaction of Age by Temperature. The range of temperatures used was most effective in altering the frequency of walking among 15-day-olds. The behavior of the oldest pups was relatively unaffected by variations in ambient temperature, however.

Figure 4 depicts the Age by Temperature by Blocks interaction, which, as in the first study, approached significance $[F(20,200)=1.51, p \cong .05]$. Friedman analyses indicated that all groups of 18-, and 21-dayolds showed a within-sessions drop in locomotion $(p<.01$ for all). The 15-day-olds tested at the two cooler temperatures persisted in their initial levels of walking. As in Experiment 1a, the youngest group tested in the warmest condition failed to show a significant intratrial reduction in ambulation. The absence of this expected effect was again due to the extreme responsiveness to temperature among the 15-day-olds. When tested at the warmest temperature, the youngest subjects showed an immediate depression of activity that constituted a "basement effect" for many of the animals. The 15-day-olds tested at $37.2^{\circ} \mathrm{C}$ tended to exhibit a within-sessions decrement in activity, however. This effect was clearly reliable $(p<.01)$ when these youngest animals from both studies were combined post hoc into one group of 23 subjects.

Finally, nest-temperature controls showed a slight day-to-day rise in their rectal temperatures. Means were $36.5^{\circ} \mathrm{C}$ among 15 -day-olds and $36.8^{\circ} \mathrm{C}$ for 21 -dayolds. This increment was reliable (Mann-Whitney U test, $\mathrm{p}<.02$ ). All subjects, regardless of age, showed hyperthermia following placement in a chamber at $37.2^{\circ} \mathrm{C}$. The mean increase in rectal temperature (in comparison to nest-temperature controls) was $1.9^{\circ} \mathrm{C}$ and no other significant changes in body temperature resulted from the treatments. When testing was conducted in the coolest incubator $\left(22.8^{\circ} \mathrm{C}\right)$, a nonsignificant hypothermia was apparent among 15-day-olds (the mean

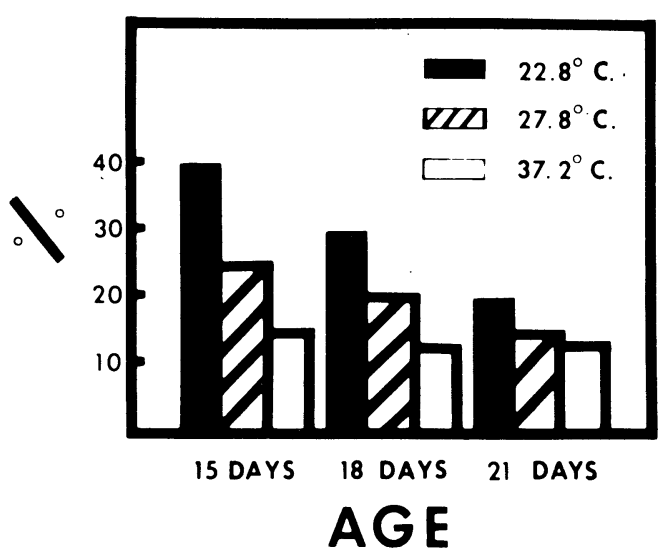

Figure 3. The percentage of observations during which walking responses were noted at a function of age and environmental temperature for Experiment $1 b$.

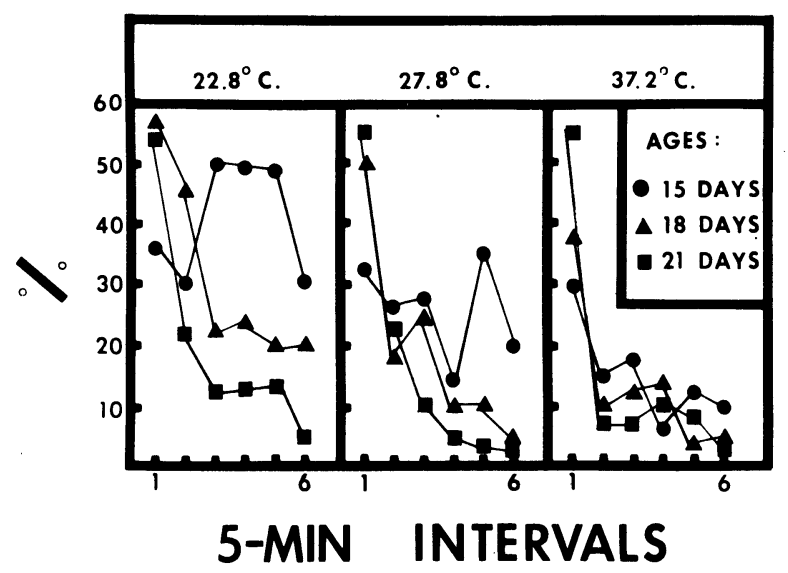

Figure 4. The effects of age, ambient termperature, and intratrial blocks upon the relative frequency of walking responses in Experiment $1 \mathrm{~b}$. 
temperature drop was $.66^{\circ} \mathrm{C}$ ). The testing conditions in the present work were only midly stressful when their effects on rectal temperature were assessed. Our treatments differentiated among age groups behaviorally, but had only a limited effect upon their rectal temperatures.

\section{DISCUSSION}

Each of the present studies provides evidence that at ambient temperatures typical of many laboratories $\left(22.8^{\circ} \mathrm{C}\right) 15-$ to 19-day-old rats ambulate in a relatively persistent manner when isolated. By Day 21, however, the pup responds much like an adult when placed in a novel environment. These older juveniles begin by locomoting, but activity is greatly reduced after only 5 or $10 \mathrm{~min}$ in the apparatus. This developmental transition, typical of rats tested in our cooler environment, replicates prior findings (e.g., Feigley et al., 1972).

As hypothesized, the current findings indicate that the activity of 15 - to 19-day-olds is more sensitive to temperature shifts than is the case with rats just a few day older. The younger pups showing elevated and nonattenuating ambulation in our coolest environment exhibited activity decrements similar to those of older animals when the ambient temperature was raised. Several other studies (e.g., Campbell \& Raskin, 1978; Goodrick, 1975; Randall \& Campbell, 1976) have shown the importance of external sources of heat in motivating pups aged 2 weeks and younger. Deprivation from nest temperatures for peiods of $2 \mathrm{~h}$ or less causes the persistent activity noted previously. Further, pups direct their movements toward sources of thermal energy when isolated at this age (Fowler \& Kellogg, 1975).

Altman, Brunner, and Bayer (1973) and Campbell, Lytle, and Fibiger (1969) postulated that inadequate forebrain development leads the 15-day-old pup to be in an aroused state and somewhat unable to inhibit responses. The current data, along with the recent findings of Campbell and his associates (e.g., Campbell \& Raskin, 1978), demonstrated this general-arousal theory to be incomplete. The isolated 2 -week-old exhibits high levels of motor activity because of its separation from intralitter cues (olfactory, thermal, and tactile). Tests that have included these important cues have uniformly shown that 2 -week-old rats are not generally hyperkinetic. The heightened activity of young pups does not indicate a failure of adaptation or habituation. This behavior pattern is also not indicative of a general arousal. Pups' activity is brought about by a temporary stimulus change or stimulus deprivation.

Finally, Williams et al. (1975) found that 2 -week-old rats do not persist in their startle reflex as in their locomotor activity. They theorized that the startle response represents elicited behavior, while locomotion is an emitted, exploratory response governed by a different set of psychological and physiological laws. It is not clear why the pattern of development is not the same for both responses, but the proposed distinction between elicited and emitted behaviors seems uncertain in this context. The relatively persistent activity of 15-day-olds seems not to qualify as emitted behavior. The locomotion is elicited by the withdrawal of intralitter stimuli and, as the present paper has shown, replacement of just one of those cues results in what appears to be the adult pattern of behavior.

\section{REFERENCE NOTE}

1. Stanley, W. C. Activity related to ambient temperature, age, and food deprivation in infant beagle dogs. Paper presented at the annual meeting of the Eastern Psychological Association, Philadelphia, 1974.

\section{REFERENCES}

Abbey, H., \& HowaRd, E. Statistical procedures in developmental studies with multiple offspring. Developmental Psychobiology, 1973, 6, 329-335.

Adolph, E. F. Ontogeny of physiological regulations in the rat. Quarterly Journal of Biology, 1957, 32, 89-137.

AlberTs, J. R. Huddling in rat pups: Group behavioral mechanisms of temperature regulation and energy conservation. Journal of Comparative and Physiological Psychology, in press. (a)

Alberts, J. R. Huddling in rat pups: Multisensory control of contact behavior. Journal of Comparative and Physiological Psychology, in press. (b)

Altman, J., Brunner, R. L., \& Bayer, S. A. The hippocampus and behavioral maturation. Behavioral Biology, 1973, 8, 557-596.

Bronstein, P. M., Dworkin, T., \& Bilder, B. Age-related differences in rats' spontaneous alternation. Animal Learning \& Behavior, 1974, 2, 285-288.

Bronstein, P. M., Neiman, H., Wolkoff, F. D., \& LEVINE, M. J. The development of habituation in the rat. Animal Learning \& Behavior, 1974, 2, 92-96.

Campbell, B. A., Lytle, L. D., \& Fibiger, H. C. Ontogeny of adrenergic arousal and cholinergic inhibitory mechanisms in the rat. Science, 1969, 166, 637-638.

Campbell, B. A., \& Raskin, L. A. The ontogeny of behavioral arousal: Role of environmental stimuli. Journal of Comparative and Physiological Psychology, 1978, 92, 176-184.

Feigley, D. A., Parsons, P. A., Hamilton, L. W., \& SPEAR, N. E. Development of habituation to novel environments in the rat. Journal of Comparative and Physiological Psychology, 1972, 79, 443-452.

Fowler, S. J., \& KellogG, C. Ontogeny of thermoregulatory mechanisms in the rat. Journal of Comparative and Physiological Psychology, 1975, 89, 738-746.

Goodrick, C. L. Adaptation to novel environments by the rat: Effects of age, stimulus intensity, group testing, and temperature. Developmental Psychobiology, 1975, 8, 287-296.

King, D. L. Effect of early experience and litter on some emotionality variables in the rat. Journal of Comparative and Physiological Psychology, 1970, 73, 436-441.

NAGY, Z. M., MurPhy, J. M., \& Ray, D. Development of behavioral arousal and inhibition in the Swiss-Webster mouse. Bulletin of the Psychonomic Society, 1975, 6, 146-148.

OкоN, E. E. The temperature relations of vocalization in infant golden hamsters and Wistar rats. Journal of Zoology (London), 1971, 164, 227-237.

Palese, R. P., \& Bronstein, P. M. Exploration and spontaneous activity in young rats. Bulletin of the Psychonomic Society, 1976, 7, 352-354.

Parsons, P. J., Fagan, T., \& Spear, N. E. Short-term retention of habituation in the rat: A developmental study from infancy to old age. Journal of Comparative and Physiological Psychology, 1973, 84, 545-553.

Randall, P. K., \& CAMPBell, B. A. Ontogeny of behavioral arousal in rats: Effect of maternal and sibling presence. Journal of Comparative and Physiological Psychology, 1976, 90, 453-459.

SIEgEL, S. Nonparametric statistics for the behavioral sciences. New York: McGraw-Hill, 1956.

Williams, J. M., Hamilton, L. W., \& Carlton, P. L. An ontogenetic analysis of two classes of habituation. Journal of Comparative and Physiological Psychology, 1975, 89, 733-737.

(Received for publication March 20, 1978.) 